\title{
Increased Serum Levels of Asymmetric Dimethylarginine and Symmetric Dimethylarginine and Decreased Levels of Arginine in Sudanese Patients with Essential Hypertension
}

\author{
Sahar Gamila Jeanette Erdmann ${ }^{b-d} \quad$ Edzard Schwedhelm ${ }^{c, e}$ \\ Khalid Hussein Bakheit $^{f} \quad$ Ihab B.B. Abdalrahman ${ }^{g} \quad$ Abdelrahim O. Mohamed $^{\mathrm{a}}$ \\ aDepartment of Biochemistry, Faculty of Medicine, University of Khartoum, Khartoum, Sudan; \\ ${ }^{b}$ Institute for Cardiogenetics, University of Lübeck, Lübeck, Germany; ${ }^{~ C D Z H K ~(G e r m a n ~ R e s e a r c h ~}$ \\ Centre for Cardiovascular Research), partner site Hamburg/Kiel/Lübeck, Hamburg/Kiel/Lübeck,

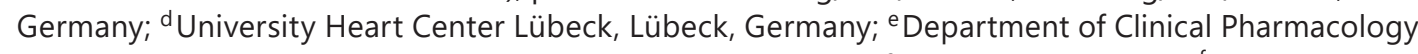 \\ and Toxicology, University Medical Center Hamburg-Eppendorf, Hamburg, Germany; ${ }^{f}$ Department \\ of Clinical Biochemistry, King Abdulaziz University, Jeddah, Saudi Arabia; ${ }^{9}$ Department of Medicine, \\ Faculty of Medicine, University of Khartoum, Khartoum, Sudan
}

\section{Keywords}

Asymmetric dimethylarginine - Primary hypertension - Association · Hypertensive patients · Sudan

\begin{abstract}
Introduction: Essential hypertension (EH) is a disease caused by various environmental and genetic factors. Nitric oxide (NO) is important for the functional integrity of the endothelium. It is produced in endothelial cells by endothelial NO synthase (eNOS) that mediates the conversion of the amino acid arginine into $\mathrm{NO}$ and citrulline. Asymmetric dimethylarginine (ADMA) acts as an inhibitor of eNOS. In contrast, symmetric dimethylarginine (SDMA) has no direct effect on eNOS but plays an important role competing with arginine for transport across the amino acid transporter. ADMA and SDMA have been found to play a central role in the development of cardiovascular diseases. Serum ADMA levels may serve as a future diagnostic marker and a target of therapy in hypertensive patients in the Sudanese population. This study aimed to investigate the relation between serum arginine, ADMA, and SDMA levels with EH in the Sudanese population. Methods: Patients $(n=260)$ with established hypertension and controls $(n=144)$ with normal blood pressure were included in this case-control study. Serum blood samples were analyzed for arginine, ADMA, and SDMA, using high-performance liquid chromatography-tandem mass spectrometry. Other laboratory data were measured using routine methods. Mann-Whitney's $U$ test and $\chi^{2}$ tests were used for continuous and categorical data, respectively. A multivariate logistic regression analysis was conducted to investigate the independent effect of multiple variables on the development of hypertension. Results:
\end{abstract}




\section{Kidney \\ Blood Pressure \\ Research}

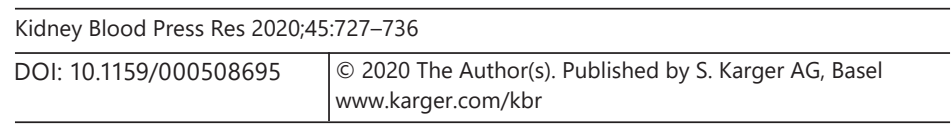

Serum arginine levels were significantly lower in the patient group than in the control group $(p<0.001)$. ADMA and SDMA levels were significantly higher in the patient group than the control group ( $p<0.001, p=0.001$, respectively). Multivariate logistic regression analysis showed that only older age, being a male, and arginine levels are independent factors controlling the development of hypertension $(p<0.001, p<0.001$, and $p=0.046$, respectively). ADMA and SDMA levels were not independent factors for the development of hypertension. Conclusions: This study demonstrated increased serum levels of ADMA and SDMA and decreased arginine levels in Sudanese patients with $\mathrm{EH}$. Lowering serum ADMA levels or increasing the arginine levels might be a novel therapeutic target in these individuals.

(C) 2020 The Author(s)

Published by S. Karger AG, Basel

\section{Introduction}

Essential hypertension (EH) is a multifactorial disease caused by various environmental and genetic factors. Despite recent advances in understanding and treating hypertension, its prevalence continues to rise. Approximately $40 \%$ of the global adult population aged 25 and above suffer from hypertension [1]. In 2011, the prevalence of hypertension in Sudan was estimated to be $20 \%$ [2]. A recent study done in 2016 has found that the prevalence of hypertension in Sudanese urban communities living in North Sudan is 35.7\% [3]. Cardiovascular diseases (CVDs) are now the main cause of death as it is responsible for one third of total deaths worldwide [4].

Nitric oxide (NO) is important for the anatomical and functional integrity of the vascular endothelium, which is essential for the prevention of atherosclerosis, hypertension, and other CVDs [5]. It is produced in endothelial cells by endothelial NO synthase (eNOS), an enzyme that mediates the conversion of the amino acid arginine into NO and citrulline [6]. NO bioavailability is dependent on the amount of free radicals and superoxide that can be formed by surrounding cells or by the enzyme itself in cases of low levels of its substrate arginine [7].

Asymmetric dimethyl arginine (ADMA) is an endogenous molecule, which differs from arginine by the addition of two methyl groups. It is formed by the methylation of arginine residues in proteins via protein arginine methyl transferases (PRMTs) [8]. There are two different types of PRMTs: type I, which results in the formation of ADMA, and type II, which results in the formation of symmetric dimethyl arginine (SDMA) [8]. Type I PRMT is activated by oxidized low-density lipoproteins [9] and elevated shear stress [10]. ADMA acts as a competitive inhibitor of the eNOS, blocking NO synthesis, and also induces the production of superoxide radical $\left(\mathrm{O}_{2}^{-}\right)$[11]. As $\mathrm{NO}$ has a high affinity for the superoxide, binding of NO to $\mathrm{O}_{2}{ }^{-}$forms peroxynitrite, which decreases the bioavailability of $\mathrm{NO}$ and leads to activation of transcription factors that are sensitive to redox signaling [12]. These factors upregulate the synthesis of endothelial cell adhesion molecules, leading to the adhesion of leukocytes to the endothelium and progression of atherosclerosis [13]. In contrast, SDMA has no direct effect on eNOS but has an important role competing with arginine for transport across the amino acid transporter, thereby reducing the substrate for eNOS [14] (shown in Fig. 1). SDMA was found to reduce the synthesis of NO in a dose-dependent manner, and this effect is reversed by treatment with arginine [15]. ADMA is eliminated by urinary excretion and metabolized by the enzyme dimethyl arginine dimethylaminohydrolase (DDAH), which converts ADMA into citrulline and dimethyl amines [16]. No metabolic pathway has been identified for SDMA so far, and it is entirely excreted in urine [17].

ADMA and SDMA play a central role in the development of CVDs. Serum ADMA levels may serve as a future diagnostic marker [18] and a goal for therapeutic intervention, and there is a significant association between ADMA and hypertension [19, 20]. Increased levels of both ADMA and SDMA are predictors of morbidity and mortality in CVDs [21]. 
Fig. 1. Role of NO, arginine, ADMA, and SDMA in the pathophysiology of endothelial dysfunction.

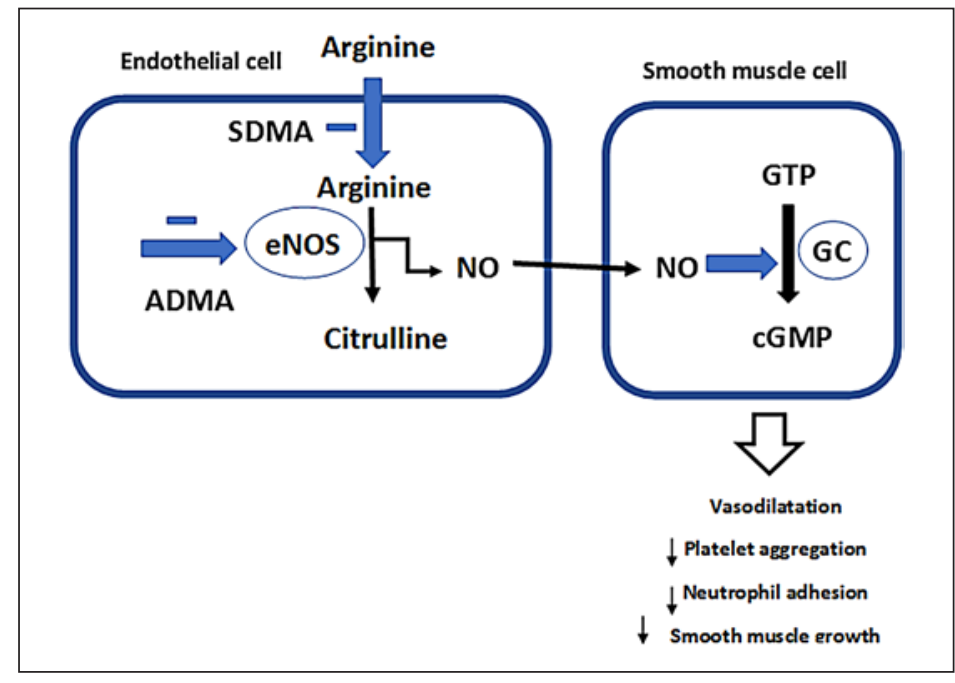

The potential contribution of ADMA and SDMA in the development of hypertension has not been previously studied in Sudan. This study aimed to investigate the association between serum arginine, ADMA, and SDMA levels with EH in patients from a Sudanese population.

\section{Materials and Methods}

This is a case control study conducted in Khartoum, Sudan, and samples were collected between February 2014 and February 2015. Hypertensive patients $(n=260)$ were enrolled in the study and recruited from Samir Health Centre, Soba University Hospital, and Fath El Rahman El Bashir Referral Clinics. Patients were selected according to the following criteria: (1) greater than 18 years of age and (2) established hypertension, defined either by chronic therapy or blood pressure greater than $140 / 90 \mathrm{~mm} \mathrm{Hg}$ according to the National Institute of Health and Care Excellence 2011 guidelines [22]. Patients were excluded from the study if they had: (1) secondary hypertension (excluded by history, clinical examination, and lab investigations) and (2) evidence of inflammatory processes (stimulus for inducible NOS). The inflammatory process was diagnosed by the presence of two of the following: tachycardia, hypotension, tachypnea, and high or low temperature [23]. Plasma levels of C-reactive protein (CRP) were also measured. (3) Patients who had proteinuria were excluded from the study as it may suggest a secondary cause of hypertension; also, patients who had evidence of urine infection (WBCs in urine $>10$ cells $/ \mathrm{mL}$ ) were excluded from the study.

Controls ( $n=144$; age, $>18$ years; blood pressure, $<140 / 90 \mathrm{~mm} \mathrm{Hg}$, without evidence of disease) were recruited from different companies and institutes in Khartoum. Full history and examination were performed with each participant in the control group to exclude any diseases. In addition, each of these participants were investigated for random blood glucose (RBG) levels, creatinine levels, lipid profile, CRP, and urine in general. Any participant with any abnormality in his investigation was excluded from the study.

The study is approved by the Ethical Committee of the Medical and Health Studies Board, University of Khartoum. Patients and control individuals were consulted about their willingness to participate in the study, and written consent was obtained. Interviews were performed, and information was obtained via a structured questionnaire on demographic data, duration of hypertension (in EH patients), family history of hypertension, risk factors 


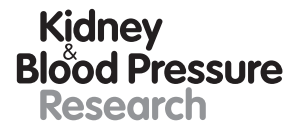

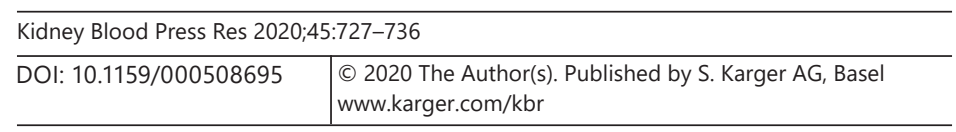

Gamil et al:: ADMA in EH Patients from Sudan

for hypertension, prior and current medication taken for EH, other medications, smoking, alcohol consumption, and other EH-associated chronic diseases such as diabetes mellitus, myocardial infarction (MI), renal diseases, hypercholesterolemia, and stroke.

Blood pressure was measured on two occasions in a quiet room after $15 \mathrm{~min}$ of rest in a supine position using a recently calibrated sphygmomanometer. Venous blood (10 mL) was drawn and divided into fluoride tubes for glucose measurement, heparin tubes for measurement of the lipid profile and creatinine, and plain tubes for arginine, ADMA, SDMA, and CRP measurements. Tubes were centrifuged at 4,000 rpm for $10 \mathrm{~min}$, and plasma and serum were collected for laboratory assays. RBG was measured immediately, and the remaining samples were stored at $-20^{\circ} \mathrm{C}$ until further analysis. Urine samples were collected in plain containers for general investigations (sugar, acetone, protein, albuminuria, and microscopic examinations).

Measurement of RBG, creatinine, lipid profile, and CRP levels was performed using BioSystems reagents (BioSystems SA, Barcelona, Spain) following routine manual methods. The qualitative (positive/negative) latex agglutination rapid test with a cutoff point of $6 \mathrm{mg} / \mathrm{L}$ was used for CRP measurements (Biosystems SA, Barcelona, Spain).

High-performance liquid chromatography-tandem mass spectrometry (Varian Inc., CA, USA) was used to determine serum levels of the guanidino compounds arginine, ADMA, and SDMA, as reported using previously validated methods [24]. In brief, $25 \mu \mathrm{L}$ of serum was diluted with stable isotope labeled L-arginine and ADMA. Subsequently, proteins were precipitated with methanol, and guanidino compounds were converted to their butyl esters. Concentrations of guanidino compounds were calculated with calibration curves (triplicates), and platewise quality controls were run in duplicates. Intra- and interassay coefficients of variation were $\leq 12 \%$ for all analyzed guanidino compounds.

Statistical analysis was performed with the Statistical Package for the Social Sciences for Windows software (SPSS, version 24.0). Categorical variables of the study group were reported as percentages and compared in the two groups using the $\chi^{2}$ test. Continuous variables were reported as means \pm standard deviations, and the Shapiro-Wilk test was used to test the normality of the continuous variables. The intergroup differences in nonnormally distributed continuous variables were compared by the Mann-Whitney U test. Multivariate logistic regression was done to clarify the independent association of demographic variables (age, sex, BMI, and smoking status) and serum levels of arginine, ADMA, and SDMA with the development of hypertension. In the patient group, association of serum levels of arginine, ADMA, and SDMA with comorbidities complicating hypertension were analyzed. A $p$ value of $<0.05$ was considered to be statistically significant in this study.

\section{Results}

In this study 260 hypertensive patients and 144 controls were recruited. The age ranged from 28 to 87 years (mean age, 59.68 years) and 19-70 years (mean age, 36.12 years) in the hypertensive patients and control group, respectively. Patients had a higher age, BMI, systolic and diastolic blood pressures, and comprised a lower percentage of males and smokers, than the control group. Around a third of the hypertensive group comprised diabetics as well, and $14 \%$ of cases were complicated by hypercholesterolemia. $9 \%$ of the hypertensive group had a history of MI, and small percentages had stroke and renal failure ( 3 and $2 \%$, respectively). None of the control group had any of these chronic diseases (Table 1).

The hypertensive group had significantly higher RBG, creatinine, triglyceride, cholesterol, and low-density lipoprotein levels, and lower high-density lipoprotein levels, than the 


\section{Research}

Table 1. Characteristics of patients and controls

\begin{tabular}{lccc}
\hline & Patients $(n=260)$ & Controls $(n=144)$ & $p$ value \\
\hline Age & $59.7 \pm 11.5$ & $36.1 \pm 10.8$ & $<0.001^{\mathrm{a}}$ \\
Males & $111(43 \%)$ & $110(77 \%)$ & $<0.001^{\mathrm{b}}$ \\
Systolic BP, mm Hg & $140.9 \pm 19.5$ & $119.3 \pm 10.8$ & $<0.001^{\mathrm{a}}$ \\
Diastolic BP, mm Hg & $82.9 \pm 11.3$ & $77.1 \pm 8.8$ & $<0.001^{\mathrm{a}}$ \\
BMI & $28.8 \pm 6.2$ & $5.1 \pm 4.1$ & $<0.001^{\mathrm{a}}$ \\
Smoking & $16(6.3 \%)$ & $40(31 \%)$ & $<0.001^{\mathrm{b}}$ \\
Diabetes & $80(31 \%)$ & - & - \\
Stroke & $8(3 \%)$ & - & - \\
Myocardial infarction & $23(9 \%)$ & - & - \\
Renal failure & $4(2 \%)$ & - & - \\
Hypercholesterolemia & $37(14 \%)$ & - & - \\
\hline
\end{tabular}

$\mathrm{BP}$, blood pressure, BMI, body mass index measured as weight $(\mathrm{kg})$ per height squared $\left(\mathrm{m}^{2}\right) .{ }^{\text {a }}$ Calculated using Mann-Whitney $\mathrm{U}$ test. ${ }^{\mathrm{b}}$ Calculated using $\chi^{2}$ test.

Table 2. Comparison of biochemical characteristics between patient and control groups
Table 3. Comparison between serum levels of arginine, ADMA, and SDMA in patient and control groups

\begin{tabular}{lccc}
\hline & $\begin{array}{l}\text { Patients } \\
(n=260)\end{array}$ & $\begin{array}{l}\text { Controls } \\
(n=144)\end{array}$ & $p$ value \\
\hline RBG, mg/dL & $128.4 \pm 66.6$ & $89.6 \pm 35.6$ & $<0.001^{\mathrm{a}}$ \\
TAG, mg/dL & $111.9 \pm 117.8$ & $64 \pm 42.7$ & $<0.001^{\mathrm{a}}$ \\
Cholesterol, mg/dL & $166.6 \pm 66.2$ & $125.3 \pm 33.3$ & $<0.001^{\mathrm{a}}$ \\
LDL, mg/dL & $116.8 \pm 71.7$ & $68.7 \pm 18.7$ & $<0.001^{\mathrm{a}}$ \\
HDL, mg/dL & $41.3 \pm 19.9$ & $51.9 \pm 15.6$ & $<0.001^{\mathrm{a}}$ \\
Creatinine, mg/dL & $1.01 \pm 0.5$ & $0.97 \pm 0.1$ & $0.06^{\mathrm{a}}$ \\
CRP $>6 \mathrm{mg} / \mathrm{L}, n(\%)$ & $86(34)$ & $11(7.9)$ & $<0.001^{\mathrm{b}}$ \\
\hline
\end{tabular}

RBG, random blood glucose; TAG, triglyceride; LDL, low-density lipoprotein; HDL, high-density lipoprotein; CRP, C-reactive protein. ${ }^{\mathrm{a}}$ Calculated using Mann-Whitney $\mathrm{U}$ test. ${ }^{\mathrm{b}}$ Calculated using $\chi^{2}$ test.

\begin{tabular}{lccr}
\hline & $\begin{array}{l}\text { Patients } \\
(n=259)\end{array}$ & $\begin{array}{l}\text { Controls } \\
(n=141)\end{array}$ & $p$ value \\
\hline Arginine, $\mu \mathrm{mol} / \mathrm{L}$ & $132.67 \pm 59.9$ & $173.89 \pm 101.3$ & $<0.001$ \\
ADMA, $\mu \mathrm{mol} / \mathrm{L}$ & $0.81 \pm 0.16$ & $0.72 \pm 0.19$ & $<0.001$ \\
SDMA, $\mu \mathrm{mol} / \mathrm{L}$ & $0.69 \pm 0.33$ & $0.62 \pm 0.24$ & 0.001 \\
\hline \multicolumn{2}{c}{$p$ values are calculated using Mann-Whitney U test. } \\
\hline
\end{tabular}

control group. The hypertensive group had a higher percentage of individuals with positive CRP (>6 mg/dL) than the controls (Table 2).

Serum arginine levels were significantly lower in the patient group than in the control group $(p<0.001)$. ADMA and SDMA levels were significantly higher in the patient group than the control group ( $p<0.001, p=0.001$, respectively) (Table 3 ).

A multivariate logistic regression model (enter mode) was done to look for the independent effect of multiple factors on the development of hypertension in this study group. This model has included demographic variables (age, sex, BMI, and smoking status) and 
Table 4. A multivariate logistic regression studying age, BMI, smoking status, serum levels of arginine, ADMA, and SDMA as independent predictors of development of hypertension
Table 5. The association of ADMA levels with comorbidities complicating hypertension in the patient group

\begin{tabular}{lcc}
\hline Parameters & $\operatorname{Exp}(\mathrm{B})(95 \% \mathrm{CI})$ & $p$ value \\
\hline Age & $1.2(1.1-1.3)$ & $<0.001$ \\
Sex (for males) & $16.4(4.4-61.9)$ & $<0.001$ \\
BMI & $1.5(0.9-1.2)$ & 0.39 \\
Smoking & $1.3(0.3-5.8)$ & 0.74 \\
Arginine & $0.99(0.98-1)$ & 0.046 \\
ADMA & $2.3(0.06-87.9)$ & 0.66 \\
SDMA & $0.9(0.2-3.8)$ & 0.91 \\
\hline
\end{tabular}

$\operatorname{Exp}(\mathrm{B})$, exponentiation of the B coefficient; BMI, body mass index. $R^{2}$ for the model $=0.76$.

\begin{tabular}{llll}
\hline & \multicolumn{2}{l}{ ADMA levels, $\mu$ mol/L } & $p$ value \\
\hline Diabetes & Yes (80) & $0.85 \pm 0.17$ & 0.02 \\
& No (180) & $0.79 \pm 0.16$ & \\
\hline Stroke & Yes (8) & $0.81 \pm 0.12$ & 0.91 \\
& No (180) & $0.81 \pm 0.17$ & \\
\hline Myocardial infarction & Yes (23) & $0.82 \pm 0.17$ & \multirow{2}{*}{0.66} \\
& No (237) & $0.81 \pm 0.16$ & \\
\hline Renal failure & Yes (4) & $1.00 \pm 0.25$ & \multirow{2}{*}{0.12} \\
\hline Hypercholesterolemia & Yes (37) & $0.82 \pm 0.17$ & \\
& No (223) & $0.81 \pm 0.16$ & 0.75
\end{tabular}

$p$ values are calculated using Mann-Whitney U test.

serum levels of arginine, ADMA, and SDMA levels as predictors of development of hypertension. The results showed that only older age, being a male, and arginine levels are independent factors controlling the development of hypertension ( $\exp (\mathrm{B})(95 \% \mathrm{CI}): 1.2(1.1-1.3)$, $p<0.001 ; \exp (\mathrm{B})$ (95\% CI): 16.4 (4.4-61.9), $p<0.001$; $\operatorname{exp(B)~(95\% ~CI):~} 0.99$ (0.98-1), $p=$ 0.046 , respectively). ADMA and SDMA levels were not independent predictors for hypertension development in this study (Table 4).

Regarding the patient group, higher ADMA levels were found in hypertensive patients complicated with diabetes mellitus $(p=0.02)$ compared with nondiabetic hypertensive patients but it was not significantly different in hypertensive patients complicated with stroke, MI, renal failure, or hypercholesterolemia (Table 5). Arginine was found to be significantly lower in patients complicated by MI versus cases not complicated by MI (108.44 \pm 48.4 vs. $135 \pm 60.4, p=0.008$ ). Arginine was not significantly different in cases complicated by diabetes, stroke, renal failure, or hypercholesterolemia (data not shown). SDMA was not associated with any of the comorbidities in the patient group (data not shown).

\section{Discussion}

This study aimed to investigate the association between arginine, ADMA, and SDMA levels with EH in the Sudanese patients. This study found lower arginine and higher ADMA and SDMA levels in the patient group compared with the control group. 


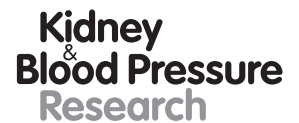

Kidney
Blood Pressure
Research \begin{tabular}{l|l}
\hline Kidney Blood Press Res 2020:45:727-736 \\
\hline DOI: 10.1159/000508695 & $\begin{array}{l}\text { @ 2020 The Author(s). Published by S. Karger AG, Basel } \\
\text { www.karger.com/kbr }\end{array}$ \\
\hline
\end{tabular}

Gamil et al.: ADMA in EH Patients from Sudan

In this study, the mean ADMA levels were $0.81 \pm 0.16 \mu \mathrm{mol} / \mathrm{L}$ in EH patients and $0.72 \pm$ $0.19 \mu \mathrm{mol} / \mathrm{L}$ in the control group. The mean level of ADMA in our control group was higher compared to previously reported means in other countries. The mean ADMA concentration was reported to be $0.52 \pm 0.11 \mu \mathrm{mol} / \mathrm{L}$ in healthy individuals from the Framingham offspring study in the USA [25], which is broadly similar to another study that reported a mean of 0.50 $\mu \mathrm{mol} / \mathrm{L}(0.39-0.63 \mu \mathrm{mol} / \mathrm{L})$ in the Netherlands [26]. The higher levels found in our study may be explained by the fact that Africans have higher ADMA levels than Europeans [27]. In the previous study, higher ADMA levels were found in Africans and were associated with a significantly reduced NO and flow-dependent dilatation compared with Europeans. This may explain the higher prevalence of CVDs in the African population [28]. ADMA levels were significantly higher in the hypertensive group than in the control group. High levels of ADMA were reported in several studies on hypertensive patients in Germany, Italy, and Egypt [2932]. Hypertensive patients were reported to have a 2-fold increase in ADMA levels and lower levels of urinary and serum nitrate compared with a control group [20]. In the present study, arginine levels were lower in the hypertensive group than in the control group. There have been no previous reports to support this finding, and the predicted value of arginine in hypertensive patients is not well studied. There are several reports of lower levels of arginine in patients with sickle cell disease and in pregnant women with preeclampsia, which has been attributed to high levels of arginase enzyme released by inflamed and damaged cells including endothelial cells $[33,34]$. Notwithstanding, several research groups have found higher levels of arginine in hypertensive patients, and they attributed the higher arginine levels to the inhibition of arginine transport inside cells, thus leading to higher plasma levels [32, 35].

ADMA levels were significantly higher in hypertensive patients with diabetes mellitus compared with patients without diabetes (Table 5). These findings are consistent with previous reports indicating that ADMA plays a role in insulin resistance and the development of diabetes mellitus [36-38].

In this study, there was no association between ADMA levels and renal failure, stroke, MI, or hypercholesterolemia (Table 5), although elevated ADMA levels were first detected in patients with chronic renal failure, and previous studies reported that ADMA is the best predictor of coronary heart disease [39] and is associated with the extent of atherosclerosis [40] and hypercholesterolemia [41-43]. The small number of cases complicated by these diseases might be a reason for not showing the correlation in this situation.

This study has a number of limitations that should be addressed: cases and controls were not matched by age and sex. Controls were younger in age with a higher percentage of males. Furthermore, controls had a lower BMI and higher percentage of smokers. To adjust for these differences, a multivariate logistic regression analysis was conducted to look for the independent effect of these and other factors along with arginine, ADMA, and SDMA levels on the development of hypertension in the Sudanese population. The analysis showed that arginine is an independent predictor for the development of hypertension but neither ADMA nor SDMA showed any significant effect on hypertension independently.

The underlying cause of increased ADMA concentration in EH is still under investigation. A possible cause is that the increased ADMA level is the result of shear stress by increased blood pressure [10]. An additional cause may be that oxidative stress induced by hypertension leads to the inhibition of DDAH and hence a reduced catabolic rate of ADMA [11]. Oxidative stress not only affects the metabolizing enzyme DDAH, but also affects PRMT isoforms [11]. Endothelial dysfunction, as a part of hypertension, also plays a major role in elevated levels of ADMA.

ADMA has recently been accepted to be an independent marker of CVD and a strong indicator of outcome and mortality alongside well-known CVD risk factors such as CRP and homocysteine. Serum ADMA levels may serve as a future diagnostic marker and a target of therapy 
in hypertensive patients in the Sudanese population. However, its clinical usefulness has not yet been established as there is uncertainty concerning the definition of a "normal" level. Furthermore, there is no specific drug available to modulate ADMA levels. One of the therapeutic measures that have been examined is exogenous arginine, which reverses the action of ADMA on the eNOS enzyme [44]. Exogenous arginine improves endothelial function and the clinical course of hypertension, which has been proved in several clinical trials [31, 32].

\section{Conclusions}

This study demonstrated increased serum levels of ADMA and SDMA and decreased arginine levels in Sudanese patients with EH. Lowering serum ADMA levels or increasing the arginine levels might be a novel therapeutic target in these individuals.

\section{Acknowledgment}

We thank all the subjects who participated in this research. Without the support of these patients the present work would not have been possible. We would like to acknowledge the excellent technical assistance and support of Sandra Wrobel. We would also like to thank the workers of Samir Health Center and the other clinics who helped in recruiting the participants of this research.

\section{Statement of Ethics}

The study is approved by the Ethical Committee of the Medical and Health Studies Board, University of Khartoum. Patients and control individuals were consulted about their willingness to participate in the study, and written consent was obtained.

\section{Disclosure Statement}

The authors declare that they have no competing interests.

\section{Funding Source}

This research has been partly funded by the German Academic Exchange Service (Deutscher Akademischer Austauschdienst) as part of a scholarship research grant for doctoral candidates and young academics and scientists (S.G.).

\section{Author Contributions}

A.O.M., J.E., and S.G. designed the study. A.O.M., J.E., K.H., and I.B. supervised the study. S.G. recruited the participants. E.S. performed the laboratory experiment. S.G., K.H., and A.O.M. wrote an early draft of the manuscript. A.O.M., J.E., E.S., and S.G. analyzed and interpreted the data. I.B. set the clinical criteria of the study. A.O.M., J.E., E.S., K.H., and I.B. revised the manuscript. All authors have read and approved the final version of the paper 


\begin{tabular}{l|l}
\hline \multicolumn{2}{l}{ Kidney Blood Press Res 2020;45:727-736 } \\
\hline DOI: 10.1159/000508695 & $\begin{array}{l}\text { C } 2020 \text { The Author(s). Published by S. Karger AG, Basel } \\
\text { www.karger.com/kbr }\end{array}$ \\
\hline
\end{tabular}

Gamil et al.: ADMA in EH Patients from Sudan

\section{References}

1 World Health Organization. Global status report on noncommunicable diseases 2010. Geneva: World Health Organization; 2011.

2 Suliman A. The state of heart disease in Sudan. Cardiovasc J Afr. 2011 Jul-Aug;22(4):191-6.

3 Bushara SO, Noor SK, Ibraheem AA, Elmadhoun WM, Ahmed MH. Prevalence of and risk factors for hypertension among urban communities of North Sudan: detecting a silent killer. J Family Med Prim Care. 2016 Jul-Sep;5(3):605-10.

4 World Health Organization. Mortality estimates by cause, age, and sex for the year 2008. Geneva: World Health Organization; 2011.

5 Vane JR, Anggård EE, Botting RM. Regulatory functions of the vascular endothelium. N Engl J Med. 1990 Jul; 323(1):27-36.

6 Furchgott RF. The 1989 Ulf von Euler lecture. Studies on endothelium-dependent vasodilation and the endothelium-derived relaxing factor. Acta Physiol Scand. 1990 Jun;139(2):257-70.

7 Alderton WK, Cooper CE, Knowles RG. Nitric oxide synthases: structure, function and inhibition. Biochem J. 2001 Aug;357 (Pt 3):593-615.

8 Pope AJ, Karuppiah K, Cardounel AJ. Role of the PRMT-DDAH-ADMA axis in the regulation of endothelial nitric oxide production. Pharmacol Res. 2009 Dec;60(6):461-5.

9 Böger RH, Sydow K, Borlak J, Thum T, Lenzen H, Schubert B, et al. LDL cholesterol upregulates synthesis of asymmetrical dimethylarginine in human endothelial cells: involvement of S-adenosylmethionine-dependent methyltransferases. Circ Res. 2000 Jul;87(2):99-105.

10 Osanai T, Saitoh M, Sasaki S, Tomita H, Matsunaga T, Okumura K. Effect of shear stress on asymmetric dimethylarginine release from vascular endothelial cells. Hypertension. 2003 Nov;42(5):985-90.

11 Sydow K, Münzel T. ADMA and oxidative stress. Atheroscler Suppl. 2003 Dec;4(4):41-51.

12 Dröge W. Free radicals in the physiological control of cell function. Physiol Rev. 2002 Jan;82(1):47-95.

13 Böger RH, Bode-Böger SM, Tsao PS, Lin PS, Chan JR, Cooke JP. An endogenous inhibitor of nitric oxide synthase regulates endothelial adhesiveness for monocytes. J Am Coll Cardiol. 2000 Dec;36(7):2287-95.

14 Closs EI, Basha FZ, Habermeier A, Förstermann U. Interference of L-arginine analogues with L-arginine transport mediated by the y+ carrier hCAT-2B. Nitric Oxide. 1997 Feb;1(1):65-73.

15 Bode-Böger SM, Scalera F, Kielstein JT, Martens-Lobenhoffer J, Breithardt G, Fobker M, et al. Symmetrical dimethylarginine: a new combined parameter for renal function and extent of coronary artery disease. J Am Soc Nephrol. 2006 Apr;17(4):1128-34.

16 Ogawa T, Kimoto M, Sasaoka K. Occurrence of a new enzyme catalyzing the direct conversion of NG,NGdimethyl-L-arginine to L-citrulline in rats. Biochem Biophys Res Commun. 1987 Oct;148(2):671-7.

17 McDermott JR. Studies on the catabolism of NG-methylarginine, NG, NG-dimethylarginine and NG, NG-dimethylarginine in the rabbit. Biochem J. 1976 Jan;154(1):179-84.

18 Siekmeier R, Grammer T, März W. Roles of oxidants, nitric oxide, and asymmetric dimethylarginine in endothelial function. J Cardiovasc Pharmacol Ther. 2008 Dec;13(4):279-97.

19 Achan V, Broadhead M, Malaki M, Whitley G, Leiper J, MacAllister R, et al. Asymmetric dimethylarginine causes hypertension and cardiac dysfunction in humans and is actively metabolized by dimethylarginine dimethylaminohydrolase. Arterioscler Thromb Vasc Biol. 2003 Aug;23(8):1455-9.

20 Surdacki A, Nowicki M, Sandmann J, Tsikas D, Boeger RH, Bode-Boeger SM, et al. Reduced urinary excretion of nitric oxide metabolites and increased plasma levels of asymmetric dimethylarginine in men with essential hypertension. J Cardiovasc Pharmacol. 1999 Apr;33(4):652-8.

21 Meinitzer A, Kielstein JT, Pilz S, Drechsler C, Ritz E, Boehm BO, et al. Symmetrical and asymmetrical dimethylarginine as predictors for mortality in patients referred for coronary angiography: the Ludwigshafen Risk and Cardiovascular Health study. Clin Chem. 2011 Jan;57(1):112-21.

22 Krause T, Lovibond K, Caulfield M, McCormack T, Williams B; Guideline Development Group. Management of hypertension: summary of NICE guidance. BMJ. 2011 Aug;343(2):d4891.

23 Bone RC, Balk RA, Cerra FB, Dellinger RP, Fein AM, Knaus WA, et al.; The ACCP/SCCM Consensus Conference Committee. American College of Chest Physicians/Society of Critical Care Medicine. Definitions for sepsis and organ failure and guidelines for the use of innovative therapies in sepsis. Chest. 1992 Jun;101(6):1644-55.

24 Schwedhelm E, Maas R, Tan-Andresen J, Schulze F, Riederer U, Böger RH. High-throughput liquid chromatographic-tandem mass spectrometric determination of arginine and dimethylated arginine derivatives in human and mouse plasma. J Chromatogr B Analyt Technol Biomed Life Sci. 2007 May;851(1-2):211-9.

25 Schwedhelm E, Xanthakis V, Maas R, Sullivan LM, Schulze F, Riederer U, et al. Asymmetric dimethylarginine reference intervals determined with liquid chromatography-tandem mass spectrometry: results from the Framingham offspring cohort. Clin Chem. 2009 Aug;55(8):1539-45.

26 Teerlink T. HPLC analysis of ADMA and other methylated L-arginine analogs in biological fluids. J Chromatogr B Analyt Technol Biomed Life Sci. 2007 May;851(1-2):21-9.

27 Melikian N, Wheatcroft SB, Ogah OS, Murphy C, Chowienczyk PJ, Wierzbicki AS, et al. Asymmetric dimethylarginine and reduced nitric oxide bioavailability in young Black African men. Hypertension. 2007 Apr;49(4): 873-7.

28 Mensah GA, Mokdad AH, Ford ES, Greenlund KJ, Croft JB. State of disparities in cardiovascular health in the United States. Circulation. 2005 Mar;111(10):1233-41. 
29 Tayeh O, Fahmi A, Islam M, Saied M. Asymmetric dimethylarginine as a prognostic marker for cardiovascular complications in hypertensive patients. Egypt Heart J. 2011;63(2):117-24.

30 Kielstein JT, Bode-Böger SM, Frölich JC, Ritz E, Haller H, Fliser D. Asymmetric dimethylarginine, blood pressure, and renal perfusion in elderly subjects. Circulation. 2003 Apr;107(14):1891-5.

31 Palloshi A, Fragasso G, Piatti P, Monti LD, Setola E, Valsecchi G, et al. Effect of oral L-arginine on blood pressure and symptoms and endothelial function in patients with systemic hypertension, positive exercise tests, and normal coronary arteries. Am J Cardiol. 2004 Apr;93(7):933-5.

32 Perticone F, Sciacqua A, Maio R, Perticone M, Maas R, Boger RH, et al. Asymmetric dimethylarginine, L-arginine, and endothelial dysfunction in essential hypertension. J Am Coll Cardiol. 2005 Aug;46(3):518-23.

33 Kim YJ, Park HS, Lee HY, Ha EH, Suh SH, Oh SK, et al. Reduced L-arginine level and decreased placental eNOS activity in preeclampsia. Placenta. 2006 Apr-May;27(4-5):438-44.

34 Morris CR, Kato GJ, Poljakovic M, Wang X, Blackwelder WC, Sachdev V, et al. Dysregulated arginine metabolism, hemolysis-associated pulmonary hypertension, and mortality in sickle cell disease. JAMA. 2005 Jul; 294(1):81-90.

35 Moss MB, Brunini TM, Soares De Moura R, Novaes Malagris LE, Roberts NB, Ellory JC, et al. Diminished L-arginine bioavailability in hypertension. Clin Sci (Lond). 2004 Oct;107(4):391-7.

36 Abbasi F, Asagmi T, Cooke JP, Lamendola C, McLaughlin T, Reaven GM, et al. Plasma concentrations of asymmetric dimethylarginine are increased in patients with type 2 diabetes mellitus. Am J Cardiol. 2001 Nov; 88(10):1201-3.

37 Stühlinger MC, Abbasi F, Chu JW, Lamendola C, McLaughlin TL, Cooke JP, et al. Relationship between insulin resistance and an endogenous nitric oxide synthase inhibitor. JAMA. 2002 Mar;287(11):1420-6.

38 Zobel EH, von Scholten BJ, Reinhard H, Persson F, Teerlink T, Hansen TW, et al. Symmetric and asymmetric dimethylarginine as risk markers of cardiovascular disease, all-cause mortality and deterioration in kidney function in persons with type 2 diabetes and microalbuminuria. Cardiovasc Diabetol. 2017 Jul;16(1):88-88.

39 Schnabel R, Blankenberg S, Lubos E, Lackner KJ, Rupprecht HJ, Espinola-Klein C, et al. Asymmetric dimethylarginine and the risk of cardiovascular events and death in patients with coronary artery disease: results from the AtheroGene Study. Circ Res. 2005 Sep;97(5):e53-9.

40 Schulze F, Lenzen H, Hanefeld C, Bartling A, Osterziel KJ, Goudeva L, et al. Asymmetric dimethylarginine is an independent risk factor for coronary heart disease: results from the multicenter Coronary Artery Risk Determination investigating the Influence of ADMA Concentration (CARDIAC) study. Am Heart J. 2006 Sep;152(3): 493.e1-8.

41 Lu TM, Ding YA, Leu HB, Yin WH, Sheu WH, Chu KM. Effect of rosuvastatin on plasma levels of asymmetric dimethylarginine in patients with hypercholesterolemia. Am J Cardiol. 2004 Jul;94(2):157-61.

42 Bode-Böger SM, Böger RH, Kienke S, Junker W, Frölich JC. Elevated L-arginine/dimethylarginine ratio contributes to enhanced systemic NO production by dietary L-arginine in hypercholesterolemic rabbits. Biochem Biophys Res Commun. 1996 Feb;219(2):598-603.

43 Böger RH, Bode-Böger SM, Szuba A, Tsao PS, Chan JR, Tangphao O, et al. Asymmetric dimethylarginine (ADMA): a novel risk factor for endothelial dysfunction: its role in hypercholesterolemia. Circulation. 1998 Nov; 98(18): 1842-7.

44 Böger RH, Bode-Böger SM, Thiele W, Creutzig A, Alexander K, Frölich JC. Restoring vascular nitric oxide formation by L-arginine improves the symptoms of intermittent claudication in patients with peripheral arterial occlusive disease. J Am Coll Cardiol. 1998 Nov;32(5):1336-44. 